\title{
НЕКОТОРЫЕ ЭТИКО-МЕДИЦИНСКИЕ АСПЕКТЫ ПРЕДОТВРАЩЕНИЯ ПОВТОРНОЙ ГИБЕЛИ ПЛОДНОГО ЯЙЦА У ЖЕНЩИН РЕПРОДУКТИВНОГО ВОЗРАСТА
}

\section{SOME ETHICAL AND MEDICAL ASPECTS OF PREVENTING REPEATED DEATH OF THE FETAL EGG IN WOMEN OF REPRODUCTIVE AGE}

\author{
N. Ruhlyada \\ S. Vinnikova \\ L. Tsechoyeva
}

Summary. The subject of the study was 60 patients from the gynecological Department No. 1 of the St. Petersburg Institute of emergency medicine named after I.I. Dzhanelidze. We have analyzed the medical history, interviewed and examined the dead woman with the fertilized egg. The main goal of the work is to adjust the treatment and management recommendations for this category of patients. As a result of the study, the following data were obtained: the average age of women with this pathology was $30.9 \pm 6.5$ years. At the time of treatment, $33.3 \%$ were $6 / 7$ weeks pregnant, and $61.7 \%$ were not registered in the women's clinic. $38.3 \%$ took medications to maintain and develop pregnancy. At least one dead fetal egg in the anamnesis was in $61.7 \%$. Changes in the vaginal flora were detected in $63.3 \%$, only $8.3 \%$ sent material for a detailed study. Antibacterial therapy was received by $93.3 \%$ without taking into account the microbiota. $20 \%$ of patients did not have a mandatory health insurance pole. $45 \%$ had a difficult financial situation, and $75 \%$ had psychological disorders at the time of admission to the hospital.

Today, there is a tendency to increase the number of dead fetal eggs in women of reproductive age, so this category of patients should be observed in a women's clinic and examined for STIs. Monitor the vaginal biocenosis using real-time $P C R$ and perform its correction. Explain to patients about the probable reasons for the development of this pathology and to recommend to the departure of their material on genetic and immunohistochemical research. Patients with a history of 2 or more dead fetal eggs deserve close attention for subsequent diagnosis of the causes of this diagnosis. The appointment of antibacterial drugs in this category of patients should be reviewed, because in the future this leads to changes in the vaginal flora. For preventive purposes, it is recommended to use the probiotic lactojinal, conduct psychological support courses after the transfer of this pathology, so that in the future they are not afraid to plan further pregnancy. Explain to foreign citizens about the possibility of obtaining a temporary health insurance pole so that they can get the necessary medical care.

Keyword: lost fetal egg, mental disorders, financial aspect, vaginal microflora, CHI policy, women's consultation, probiotic, psychological support.
Рухляда Николай Николаевич

Д.м.н., профессор, ФГБОУ ВО «Санкт-Петербургский государственный педиатрический медичинский университет» Минздрава России Винникова Симона Викторовна

Аспирант, ФГБОУ ВО «Санкт-Петербургский государственный педиатрический медичинский университет» Минздрава России simona.vinnikova@yandex.ru

Цечоева Лейла Шахмурзаевна

К.м.н., ассистент, ФГБОУ ВО «Санкт-Петербургский государственный педиатрический медицинский университет» Минздрава России

Аннотация. Предметом исследования стали 60 пациенток из гинекологического отделения № 1 СПб НИИ скорой помощи им. И.И. Джанелидзе. Нами были проанализированы истории болезни, опрошены и обследованы женщины с погибшим плодным яйцом. Основной целью работы корректировка проводимого лечения и рекомендаций ведения данной категории больных. В результате исследования получены следующие данные, средний возраст женщин с данной патологией составил $30,9 \pm 6,5$ лет. На момент обращения у $33,3 \%$ срок беременности был 6/7 нед., $61,7 \%$ не состоят на учете в женской консультации. Лекарственные препараты для поддержания и развития беременности принимали 38,3\%. Хотя бы одно погибшее плодное яйцо в анамнезе было у 61,7\%. Изменения во флоре влагалища выявлено у 63,3\%, только 8,3\% направляли материал для детального исследования. Антибактериальную терапию получали 93,3\% без учета микробиоты. Полюса обязательного медицинского страхования не было у 20\% пациенток. 45\% имели затрудненное финансовое положение, а психологические расстройства на момент обращения в стационар наблюдалось у $75 \%$.

Ключевые слова: погибшее плодное яйцо, психические расстройства, финансовый аспект, влагалищная микрофлора, полюс ОМС, женская консультация, пробиотик, психологическая поддержка. 


\section{Ввемение}

$\mathbf{H}$ а сегодняшний день под погибшим плодным яйцом понимают как патологический симптомокомплекс, включающий нежизнеспособность плода (эмбриона); патологическую инертность миометрия; нарушения в системе гемостаза [1]. Данная патология остается одной из наиболее важной составляющей среди репродуктивных потерь, и ее удельный вес составляет 10-20\%. Впервые внутриутробная гибель плода без его элиминации из полости матки на сроке беременности более 6-7 мес. упоминается Н. Oldham и A. MacClintok, они применили термин «missed labour» В 1847 г. В1872 г. был предложен другой термин «missed abortion», используемый акушерами-гинекологами и по настоящее время для обозначения аналогичной ситуации, при которой гестационный срок был менее 6-7 нед. Внутриутробная задержка погибшего плода или эмбриона сопровождается снижением сократительной функции матки и гемостатическими нарушениями в организме матери. В I триместре в 75\% случаев сначала происходит гибель плода, только после появляются симптомы угрозы прерывания беременности или выкидыша. Для данной патологии характерно отсутствие пролиферативных и метаболических процессов с участием клеточно - тканевых элементов плодного пузыря, по причине развития дистрофических и некротических изменений в нем. Главным клиническим признаком погибшего плодного яйца является стертая картина субъективных проявлений нарушения беременности на фоне стабилизация размеров матки и несоответствие сроку беременности [2].

Причины развития погибшего плодного яйца многочисленные и часто бывают комплексные. Одно из первых мест занимают хромосомные аберрации. Аномальный кариотип находят 60-75\% случаев в материале соскоба из полости матки [1-6]. До 30\% гормональные нарушения в организме женщины могут привести к развитию погибшего плодного яйца. Определенную роль инфекционным агентам. У 52,5\% пациенток с данной патологией выявляют с помощью ПЦР вирусно-бактериальную флору, в 20\% случаев моноинфекцию, могут быть случаи микс - инфекции [2].

При оценивании чувствительности эмбриона или плода к повреждающим факторам, чем меньше срок беременности, тем эта чувствительность выше. Чувствительность уменьшается неравномерно на протяжении внутриутробного развития. Выделяют критические периоды в течении беременности, когда плодное яйцо, эмбрион, плод особенно уязвимы для неблагоприятных условий (прием лекарственных средств, стрессы, психические расстройства): период имплантации (7-12-й день), период эмбриогенеза (3-8-я неделя), период формирования плаценты (до 12 нед.), период формирования важнейших функциональных систем плода (20-24 нед.) $[2,5]$.

Диагноз ставят на основании данных ультразвукового сканирования при отсутствии сердцебиения плода. При УЗИ исследовании выделяют несколько вариантов неразвивающейся беременности. Наиболее распространенным вариантом является анэмбриония, т.е. отсутствие эмбриона в полости плодного яйца после 7 нед. беременности. Также есть другая эхографическая картина неразвивающейся беременности - «замерший плод», когда визуализируется плодное яйцо и эмбрион обычной формы и размеров без признаков жизнедеятельности [1,2,7-9].

Социально-экологические факторы (состояние общества, образ жизни, профессиональные условия, семейное положение, экологические факторы, а также вредные привычки) оказывают влияние на репродуктивную функцию женского организма. По классификации С.И.Слепцовой, этиологические факторы подразделяются на медицинские и социально-средовые, связанные как с организмом женщины, так и с организмом мужчины, и с особенностями развития плода. Л.К. Хван утверждает, что в формировании любой патологии одним из наиважнейших факторов являются состояние окружающей среды и условия жизни людей. Здоровье репродуктивной системы населения служит индикатором экологического и социального фона и может быть моделью для оценки влияния экологических и социальных факторов на организм женщин. Одним из проявлений нарушений экологического равновесия и/или социального дисбаланса является погибшего плодного яйца $[10,11]$.

Тактика ведения пациенток на сегодняшний день заключается в выявлении наиболее вероятных факторов гибели эмбриона (плода). Предгравидарная подготовка направлена на устранение или ослабление действия выявленных факторов вне и во время беременности (обследование пациенток, планирующих беременность, проведение лечебно-профилактических мероприятий, направленных на ликвидацию инфекционного процесса, проведение специфической противовоспалительной терапии в сочетании с иммунокорректорами, генетическое консультирование женщин, гормональная терапия при эндокринном генезе замершей беременности). Немногие авторы указывают на необходимость нормализация психического состояния женщины (седативные средства, пропаганда здорового образа жизни - отказ от курения, алкоголя, наркотиков, отказ от беспорядочных половых связей, ведение здорового образа жизни $[1,2,12-15]$.

Главной проблемой является то, что пациентки с погибшим плодным яйцом не обследуются, и не со- 


\section{Учет в женской консультации}

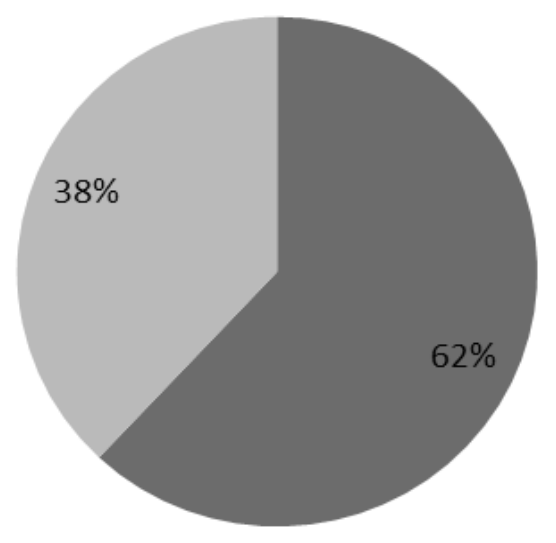

- Не состоят

Состоят

Диаграмма 1. Учет женщин в женской консультации по поводу беременности.

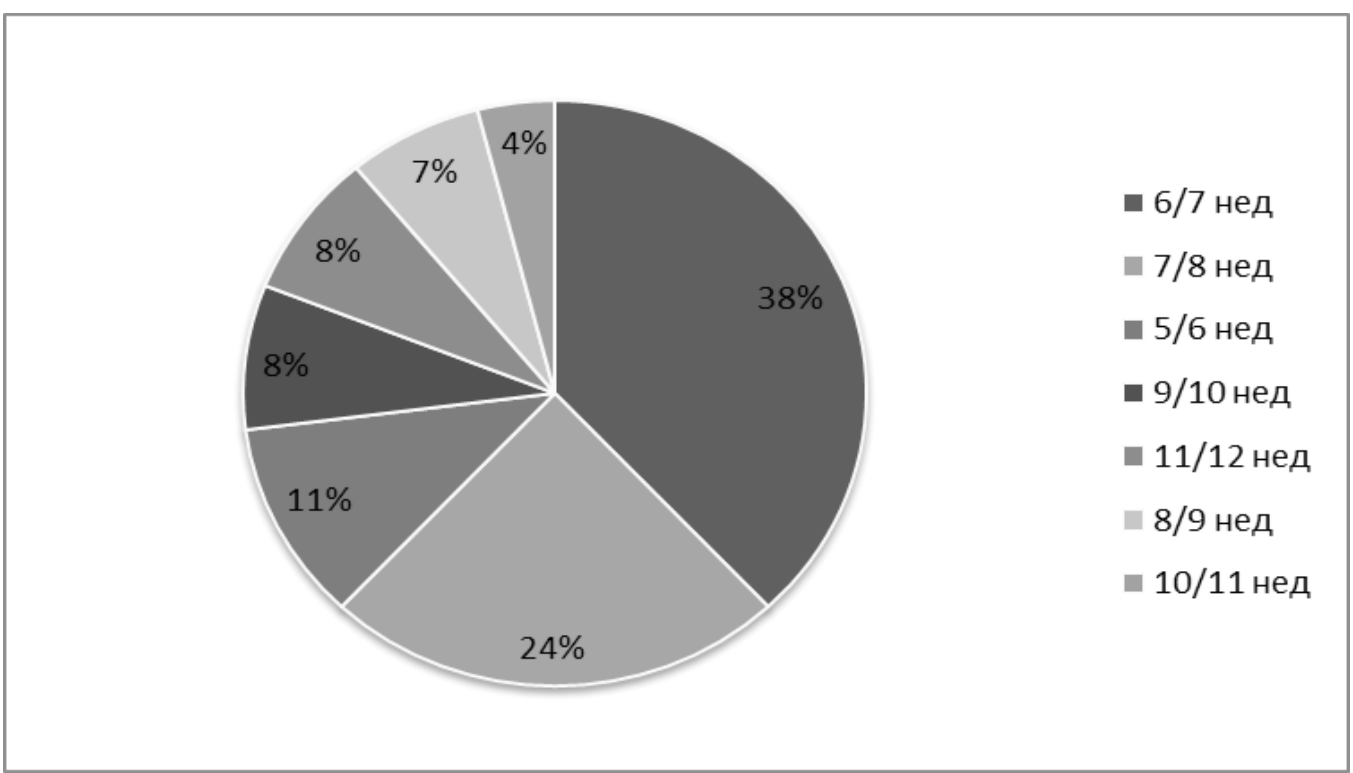

Диаграмма 2. Срок беременности по последним менструациям.

стоят на учете в женской консультации. Диагноз погибшее плодное яйцо ставят в основном по результатам УЗИ и уровню ХГЧ в крови. Погибшее плодное яйцо развивается до 6/7 недель срока беременности. Пациентки не обращаются в женскую консультацию на данном сроке беременности и если обращаются, то на сегодня появилась тенденция к уменьшению проведения у них ультразвукового исследования органов малого таза и назначения поддерживающей гормональной терапии. Кровь на ХГЧ берут при ранних сроках и смотрят ее в динамике для исключения внематочной беременности. Кроме того, не уделяют внимание влагалищной флоре, особенно у тех пациенток, у которых уже случилась данная патология. После опорожнения полости матки назначается антибактериальная терапия без определения инфекционного агента во влагалище. Крайне редко материал отвозится пациентками на генетическое и иммуногистиохимическое исследо- 


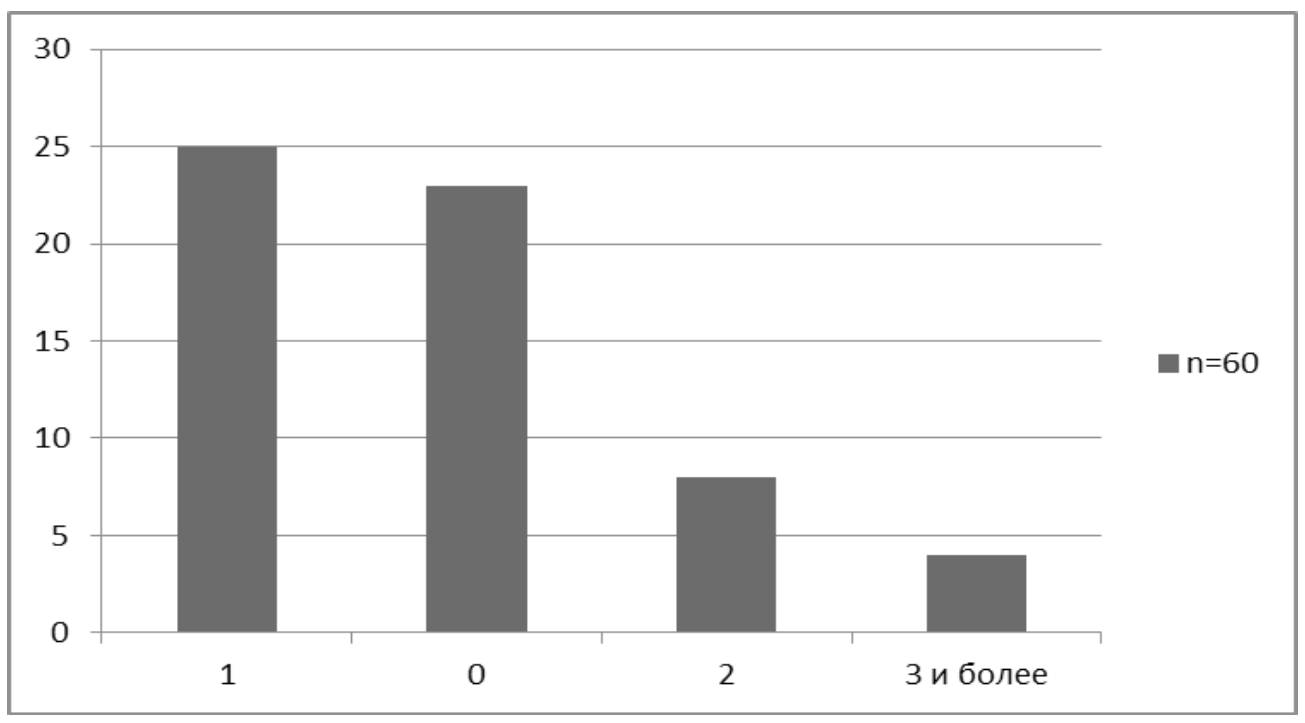

Рис. 1. Распределение пациенток по количеству предыдущих погибших плодных яиц.

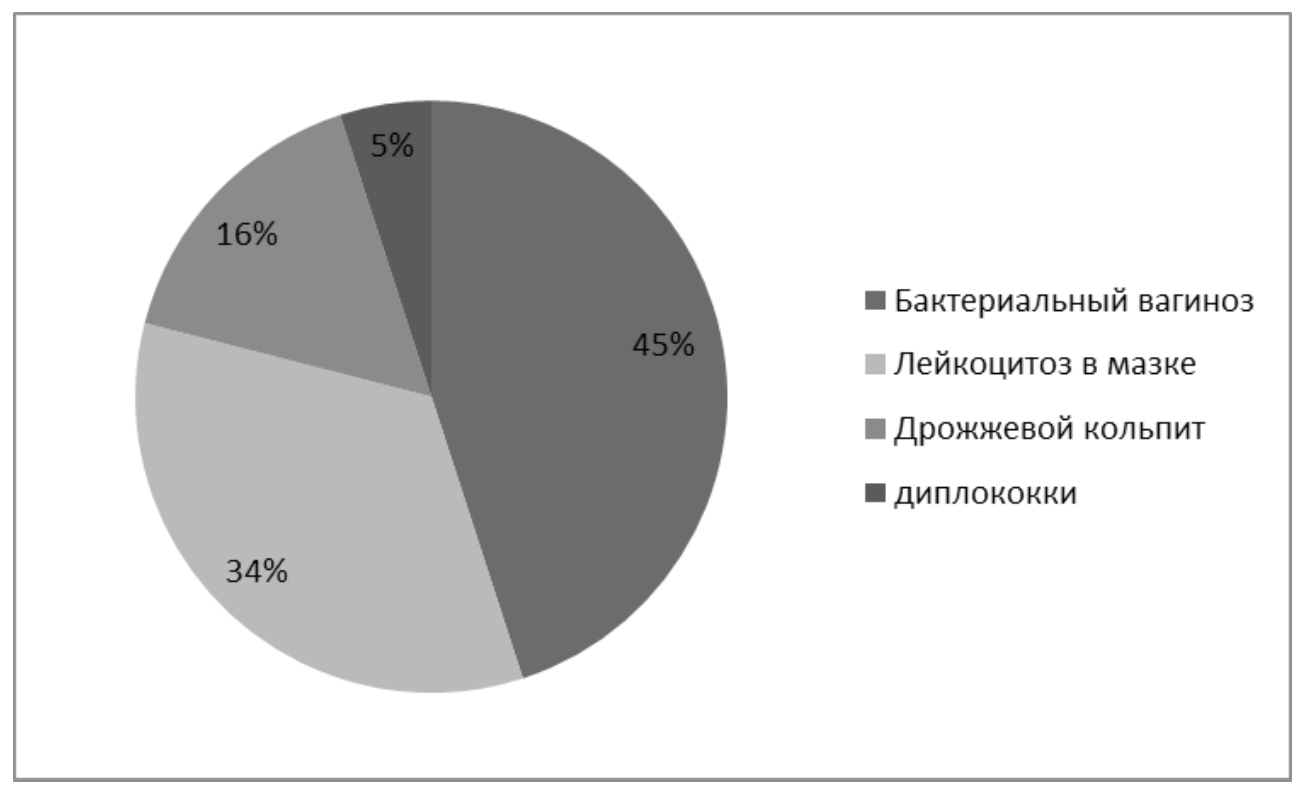

Диаграмма 3. Мазок на влагалищную флору

вание. Помимо этого, таким пациенткам не оказывается психологическая помощь. После постановки данного диагноза пациентки чаще всего предоставлены «самой себе» и они очень тяжело переживают данную ситуацию. Также является немало важным финансовый аспект данного вопроса. Большинство анализов для обследования влагалищной флоры и лекарственные препараты для поддержания и развития беременности стоят достаточно дорого, и немногие пациентки могут себе позволить, особенно иностранные граждане, которые не имеют полиса ОМС.

\section{Lе^ь исслеАования}

Скорректировать рекомендации по лечению и ведению женщин с погибшим плодным яйцом.

\section{Материалы и метолы}

Проведен анализ историй болезней, опрос и проспективное исследование женщин ( $\mathrm{n}=60)$ репродуктивного возраста (средний возраст 30,9 \pm 6,5 лет), поступивших в НИИ скорой помощи им. И.И. Джанелидзе 


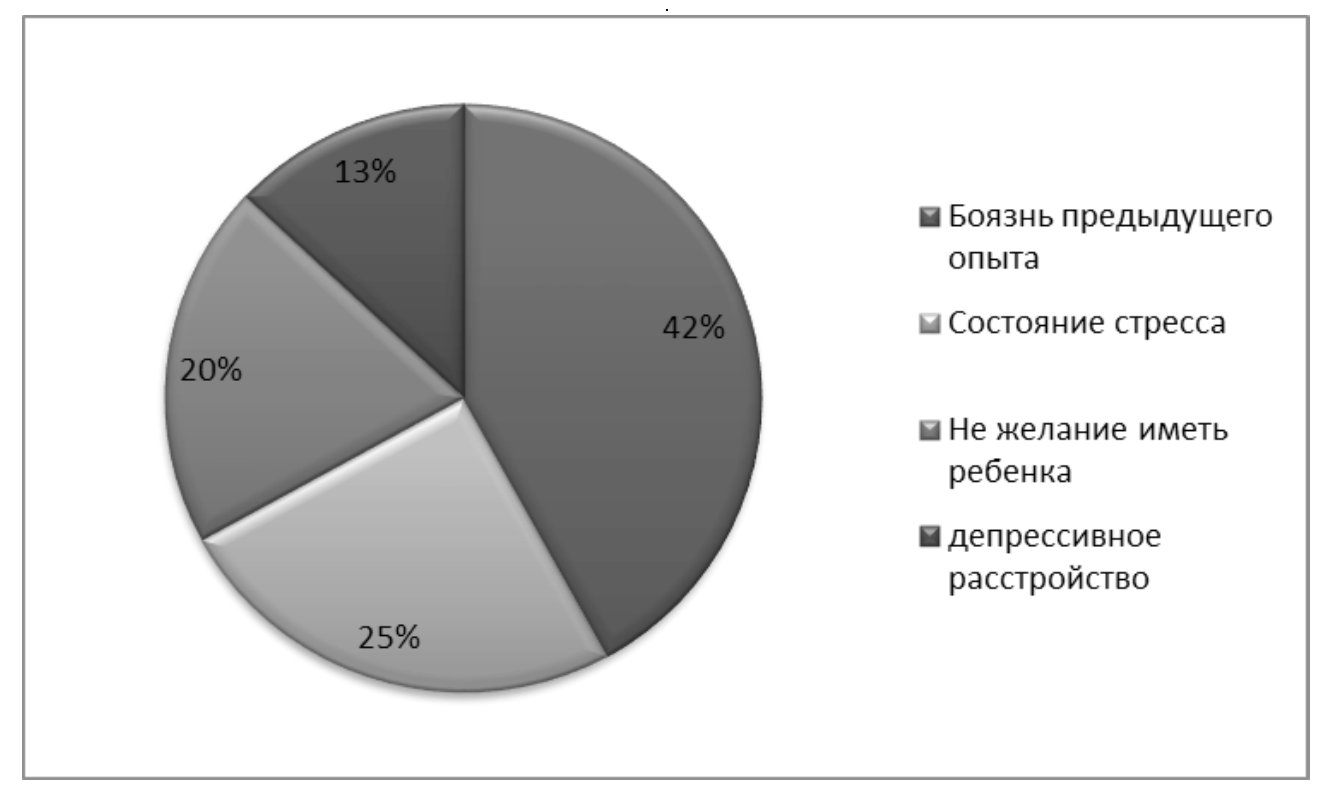

Диаграмма 4

В гинекологическое отделение на стационарное лечение с диагнозом погибшим плодным яйцом.

\section{Результаты}

В результате исследования выявлено, на учете в женской консультации по поводу беременности состоят только 38,3\%, что наглядно видно на диаграмме 1. Причиной этому является, что средний срок постановок на учет в ЖК 8/9 недель беременности. И поэтому большинство женщин либо не обращаются в женскую консультацию, либо им не оказывают внимание (не берут кровь на ХГЧ, не делают УЗИ м/таза), либо нет финансовой возможности обратиться к врачу.

Лекарственные препараты для поддержания и развития беременности принимают $38,3 \%$. В основном это препараты утрожестан и дюфастон. Остальные препараты не принимают, потому что 41,7\% пациенток не обращались к врачу и не знали о необходимости их приема. 11,7\% пациенток были эти препараты назначены, но они лично не считали их необходимыми для сохранения и развития беременности. Они полагали что гормональные препараты могут негативно сказаться на их здоровье. 8,3\% не могли по финансовым причинам приобрести эти препараты.

На диаграмме 2 представлены сроки беременности по первому дню последних месячных.

у большинства пациенток $(61,7 \%)$, как показано на рисунке 1, было в анамнезе хотя бы одно погибшее плодное яйцо.
При исследовании микрофлоры влагалища были выявлены различные изменения у 38 пациенток (63,3\%), что более наглядно представлено на диаграмме 3.

8,3\% пациентки отвезли материал соскоб на иммунногистеохимическое и генетическое исследования в МГЦ, ин.им. Отто. 91,7\% не стали отправлять на исследования, особенно те, которые имели в анамнезе 2 и более погибшее плодное яйцо.

После опорожнения полости матки 93,3\% женщин получали антибактериальную терапию без учета микробиоты, из них 20\% пациенток имели физиологический лейкоцитоз в крови и 16,7\% лейкоциты были в пределах нормы.

Также у 20\% пациенток, а именно иностранные граждане, на момент обращения не было полюса обязательного медицинского страхования и такие пациентки не могли обратиться в женскую консультацию для получения полноценного обследования и консультации. $45 \%$ имели затрудненное финансовое положение.

У 75\% пациенток наблюдались психологические расстройства на момент обращения в стационар, что представлено на диаграмме 4.

\section{ОбсужАение}

Большинство пациенток не обращались в женскую консультацию при подозрении на беременность и наличие положительного результата теста на ХГЧ. Для ранней диагностики патологии нужно прово- 
дить ультразвуковое исследование, гормональную терапию, особенно у тех, у которых в анамнезе есть погибшее плодное яйцо и хронический эндометрит. Одним из достоверных методов исследования является ПЦР влагалищной микробиоты в режиме реального времени для выявления инфекционного агента, потому что у 63,3\% пациенток до опорожнения полости матки наблюдался кольпит по результатам мазка на флору. Данный метод позволит в течение короткого времени провести качественный и количественный анализ состава флоры и в последующем корректировать лекарственными препаратами такие, как пробиотики и если необходимо антибактериальные препараты.

Помимо этого, большинство пациенток имели расстройства психики в связи со сложившейся ситуацией. Им эмоционально трудно понять и осознать, что с ними это произошло. Женщинам приходится самим преодолевать эту ситуацию. Были и те, кто находился в состоянии депрессии, стресса и не желали иметь ребенка. На момент выписки больше половины женщин боялись планировать следующую беременность, они опасались повторения ситуации, особенно те, кто в анамнезе имел уже погибшее плодное яйцо.

Также финансовый аспект сыграл определенную роль, т.к. не все имеют возможность приобрести лекарственные препараты для поддержания и развития беременности, и пройти необходимые обследования. Иностранные граждане, обратившиеся в стационар, не имели медицинского полюса и не могли получить все необходимые обследования раннее из-за отсутствия финансовых средств.

\section{Зак^ючение}

Наблюдается тенденция к увеличению количества погибшего плодного яйца у женщин репродуктивного возраста, их необходимо наблюдать в женской консультации и нужно обязательно обследовать на ИППП, исследовать и контролировать биоценоз влагалища с помощью ПЦР в режиме реального времени, при необходимости провести его коррекцию. Обязательно пациенткам рассказывать о возможных причинах развития у них патологии и с целью рекомендации отправления их материала на генетическое и иммуногистиохимическое исследования. Внимание должны заслуживать пациентки, имеющие в анамнезе 2 и более погибшего плодного яйца, с целью последующей диагностики причины развития данного диагноза. Также нужно пересмотреть необходимость назначения антибактериальных препаратов данной категории пациенток, потому что в последующем это может привести к изменению влагалищной флоры, и кишечной. С профилактической целью для исключения повторного развития погибшего плодного яйца рекомендуется применение пробиотика лактожиналь.

Таким пациенткам необходимо проводить курсы психологической поддержки после перенесения данной патологии, чтобы в дальнейшем они не боялись планировать дальнейшую беременность. При тяжелых расстройствах психики назначение седативных препаратов.

Иностранным гражданам рассказывать о возможности получения временного полюса медицинского страхования, чтобы они могли обращаться в женскую консультацию или стационар, для получения необходимых рекомендаций и лечения.

\section{ЛИТЕРАТУРЫ}

1. Радзинский В.Е, Неразвивающаяся беременность. Методические рекомендации МАРС (Междисциплинарной ассоциации специалистов репродуктивной медицины) / Радзинский В. Е., Макцелова С. А. и др.-М.: Редакция журнала StatusPraesens, 2015-48 c.

2. Агаркова И.А., Неразвивающаяся беременность: оценка факторов риска и прогнозирование/ Агаркова И. А.— Медицинский альманах № 4 (13) ноябрь 2010- c. 82-88.

3. Sugiura-Ogasawara M. et al. Abnormal Embryonic Karyotype is the Most Frequent Cause of Recurrent Miscarriage // Hum. Reprod. 2012 Vol. 27 (8). P. $2297-2302$. [PMID: 22661547].

4. Suzumori N., Sugiura-Ogasawara M. Genetic factors as a cause of miscarriage // Curr. Med. Chem. 2010 Vol. 17 (29). P. 3431-3437. [PMID: 20712563].

5. Косарев В. В. Фармакология и лекарственная терапия/ Косарев В. В., Бабанов С. А. Астахова А. В.—Справочник. М.: Эксмо, 2009.470 c.

6. Puscheck E.E., Scott Lucidi R. FACOG Early Pregnancy Loss. Practice Essentials / Updated: Sep 29, 2014 — URL: http://reference.medscape.com/article/266317overview).

7. Боровкова Е.И., Мартынова И. В. Самопроизвольный выкидыш: состояние изученности вопроса // Исследования и практика в медицине. Т. 1 № 1, 2014 C. $52-56$.

8. Doubilet P.M. et al. Editor Diagnostic Criteria for Nonviable Pregnancy Early in the First Trimester For the Society of Radiologists in Ultrasound Multispecialty Panel on Early First. Trimester Diagnosis of Miscarriage and Exclusion of a Viable Intrauterine Pregnancy // NEJM. 2013 Vol. 369 P. 1443

9. Основы ультразвуковой фетометрии: Практическое пособие для врачей / А. Ю. Блинов, М. В. Медведев. М.: Реал Тайм, 2012 <136 с.

10. Степанян Л. В. Неразвивающаяся беременность: этиология и патогенез./ Степанян Л. В., Синчихин С. П., Мамиев 0. Б.- Астраханский медицинский журнал 3 Том 6, 2011 г.- - $48-51$ 
11. Предупреждение репродуктивных потерь: стратегия и тактика. Избранные материалы Образовательного семинара «Инновации в акушерстве и гинекологии с позиций доказательной медицины»: Информационный тень / Под ред. В. Е. Радзинского. М.: Редакция журнала StatusPraesens, 2014 <24 с.

12. Димитрова В.И. Повторится ли неразвивающаяся беременность? Программа действий./ Димитрова В. И., Димитрова Д. А.-Вестник РУДН, серия Медицина, 2013, № 5- C51-54.

13. Gynaecology. Rukovodstvo to the practical training: a training manual / V. E. Radzinsky. 3 ed. — Moscow: GEOTAR-media, 2013.—P. 552.

14. Makeeva D. A. Citomorfometricheskoe prediction of miscarriage-katege // Dissertation of the Ph D.—M., 2011. — P. 22.

15. Evaluation and treatment of recurrent pregnancy loss / The Practice Committee of the American Society for Reproductive Medicine // Fertil. Steril. 2012 Vol. 98 P. 1103-1111. [PMID:22835448].

( Рухляда Николай Николаевич, Винникова Симона Викторовна ( simona.vinnikova@yandex.ru),

Цечоева Лейла Шахмурзаевна.

Журнал «Современная наука: актуальные проблемы теории и практики»

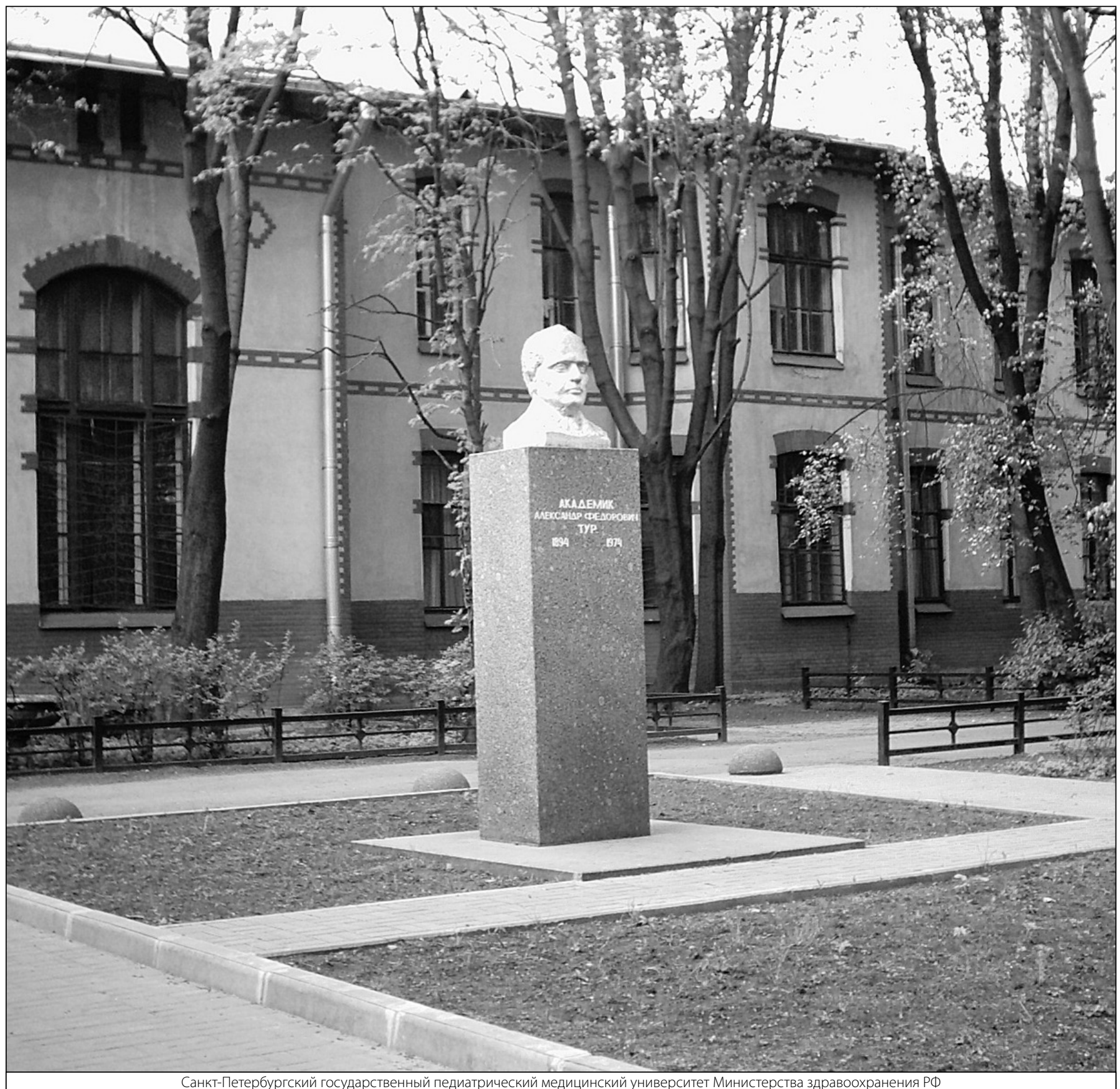

